\title{
LOCAL IMPACTS OF DOMINANT COMPANIES AND THE LEVEL OF DOMINANCE
}

\author{
Tamás Dusek ${ }^{1}$ \\ Judit Petra Koltai ${ }^{2}$ \\ Veronika Poreisz ${ }^{3}$
}

DOI: https://doi.org/10.31410/ERAZ.2019.63

\begin{abstract}
One of the most important categories of local impact studies is the investigations about the roles of a large company in the life of a small and medium-sized towns. The first part of this paper analyses this question on a conceptual, theoretical level and by the help of literature review. A systematic overview will be given on the different roles of big companies, such as in the field of economy, labour market, infrastructure, land use, traffic, local services, local taxes, demography, culture, milieu, lifestyle, politics, education, tourism and others. There can be both positive and negative side of the dominance, for example local labour market can be more stable and more vulnerable at the same time. There is a scarcity of the empirical research on these questions, mainly due to the complexity and the business secret character of some detail. The second part of the paper gives a comparative analysis about the role of Audi Hungary Company in the western Hungarian medium-sized town, Györ, which is the sixth biggest settlement in Hungary. It is an interesting test case, because the role and importance of the Audi is significantly larger than in other big companies in similar city size category in Hungary, but its weight is not extremely large in international comparison.
\end{abstract}

Keywords: local economic impact, Györ, Audi, impact analysis methodology.

\section{INTRODUCTION}

$\mathrm{T}$

he role of a large company in the life of a small and medium-sized town is an important and old research area of regional economics. Both analytical and empirical sides of the various question were in the past many times examined, but the latter, empirical part is more popular, in the form of case studies. This paper amalgamates analytical and empirical approaches, as the first part analyses the question on a conceptual, theoretical level and by the help of literature review. A general overview will be given on the different roles of big companies, such as in the field of economy, labour market, infrastructure, land use, traffic, local services, local taxes, demography, culture, milieu, lifestyle, politics, education, tourism and others. The second part of the paper gives a comparative analysis about the role of Audi Hungary Company in the western Hungarian medium-sized town, Győr, which is the sixth biggest settlement in Hungary.

\section{GENERAL IMPACT OF A COMPANY ON LOCAL ECONOMY}

Companies, as any other economic units, have various and manifold impacts on local economy. The characters and intensity of these impacts are dependent from the size, nature and branch of the company. For example, impact of an assembly plant and a headquarter of a multinational company have entirely different character. Classification and examples of total local effect of

Széchenyi István University, Hungary, Győr, Egyetem tér 1

Széchenyi István University, Hungary, Győr, Egyetem tér 1

Széchenyi István University, Hungary, Győr, Egyetem tér 1 
a company is summarized in Table 1 . As regards the economic effect in a narrower sense, it is classified in Table 2. Of course, it is possible to classify these effects in many other alternative ways, such as short run and long run, monetary and non-monetary, direct and indirect, tangible and intangible effects and so on.

Table 1: Classification and examples of the local effects of a company Source: Garrido-Iserte - Gallo-Rivera (2010) (modified)

\begin{tabular}{|c|c|}
\hline Local effects of a company upon: & Example \\
\hline Economy & $\begin{array}{l}\text { Effects upon regional income, industrial structure, job market, labor } \\
\text { mobility }\end{array}$ \\
\hline Demography & Effects upon population growth, population structure and upon mobility \\
\hline Politics & $\begin{array}{l}\text { Changes in the political structure, an increase in citizen participation, } \\
\text { improvement in the organization of political processes; lobbying }\end{array}$ \\
\hline Infrastructure & Effects upon housing, traffic, healthcare services, retail \\
\hline Culture & Influence upon cultural environment \\
\hline Attractiveness & Influence upon the local image, local identity \\
\hline Education & $\begin{array}{l}\text { Effect upon participation rate, changes in its quality, partnership } \\
\text { with vocational and university level, contacts between company and } \\
\text { educational institutions }\end{array}$ \\
\hline Social aspects & Effect upon the quality of life, influence upon the local image and identity \\
\hline
\end{tabular}

Table 2: Classification and examples of economic effects of the companies Source: Garrido-Iserte - Gallo-Rivera (2010) (modified)

\begin{tabular}{l|l}
\hline Economic effects of a company & Example \\
\hline Employment at the company & Number of jobs \\
Company income & Wages and salaries, social security costs, profits, taxes \\
Expenditures & Purchase of goods and services from local companies \\
Generation of business & Location choices of firms, companies \\
Knowledge marketing & Creation of knowledge, business atmosphere \\
Tourism & Tourism induced by the presence of the company \\
\hline \hline
\end{tabular}

The various subsystems listed in Table 1 are directly or indirectly interrelated in different ways. For example, the increase of population due to the job opportunities generates higher consumption that has a further impact on the job market, which in turn generates feedback effects on the demographic and infrastructure subsystems. (Garrido-Iserte-Gallo-Rivera, 2010)

\section{TWO APPROACHES OF THE LOCAL ECONOMIC IMPACT STUDIES}

Professional literature offers at least two approaches to examine the role of economic entities in a local economy. According to the first - and most widespread - approach, economic impact is defined as the difference between actual economic activities (production, earnings, employment and a general business atmosphere) and economic activities assumed to exist without the given economic entity (Beck et al., 1995). The first approach shows what would happen if the given economic entity did not exist at all, how much less earnings would be made, how much less the number of employees would be and what other economic changes would be present. At the same time, these can be compared to the opportunities arising from the fact that the resources used by the given company could be utilised elsewhere. Without such a comparison, nearly all players of the economy would have a positive role and can, accordingly, emphasise their positive role in local economy, as they do have some employees and make a certain amount of earnings in the course of their activities. For example, a new assembly plant reduces the human resource available for the other businesses, and makes it more difficult or expensive for them to expand their 
capacities. Grime and Starkie (1968) shows that a totally new factory contributes extremely little direct impact on the unemployment problem. Mainly former employees of existing, other firms became employees of the new firm.

In other words, the second approach takes into account, in addition to the absolute or "gross" impact, the potential production, income, employment and other impacts potentially made from alternative utilisation scenarios of the economic entity's resources, i.e. examines the net impact - which may even be negative. However, before conducting the second approach, firstly a prior and temporary absolute investigation should be made. (Barrow - Hall, 1995; Drucker - Goldstein, 2007)

Both approaches have shortcomings: the first approach has tendency to inflate the impacts, the second one requires the use of several shaky and problematic assumptions. Due to the ideological reasons, the second type of study is extremely rare, because companies (or other actors, like universities, ports, sport clubs, festivals and so on) are not interested in such type of research. They always want to stress on their positive impacts on the local economy, therefore they are interested in the first type of studies. These are the characteristic features of studies by consultant companies and agencies made for public relation, marketing reasons or for obtaining subsidies, tax abatements or other form of legally guaranteed advantage in competition.

\section{TYPES OF LOCAL ECNOMIC IMPACTS AND EXAMINATION METHODS}

By the 1970s there has already been a great amount of theoretical and empirical literature on local economic impact of different economic units and how to examine them. The analyses and methods can be classified in many ways; there is no one general and unified methodology. A unified methodology cannot be formed as local businesses vary greatly in size and quality, have different structures, and they have very different characteristics and spatial relations. Completely different factors may be important when analysing an administrative unit, a paper producing company, a sport club or event, a port or airport, a prison, a university; or when a business is located in a small town with ten thousand or in a metropolis with ten million inhabitants. Research methods may also vary due to the goal of a research, as statistical data, sampling, econometric models, surveys and expert interviews are suitable to provide answers to very different research questions. Data availability may also restrict applicable methods.

Thus, this part of the paper shall not aim to standardise possible impacts and methods based on previous literature and earlier empirical works, but simply to emphasise points relevant to the analysis. This is useful because actual researches may use the same terms to describe different things, or they may operate a concept differently, or they may be analysing the very same things under different terms. At the same time some studies describe their methods and sources of data rather vaguely, which makes it difficult to analyse and generalise data.

Economic impact analysis usually describes two, three or four types of impact. Consequently, there are four general terms: direct impact, indirect impact, induced impact and catalytic impact.

1. Direct impact: output, income and jobs resulting from the investments and operation of a given economic unit.

2. Indirect impact: income and employment generated at local businesses that offer inputs for a given economic unit.

3. Induced impact: local income and employment generated by the multiplier effect resulting from spending the directly and indirectly created income. 
4. Catalytic impacts: changes in local economy generated by the operation of a given economic unit. This may include increased attractiveness of investment, local image, effects on the structure and composition of local economy, impacts on workforce qualification, education, dwellings and real estate market, local services and attracting visitors. This effect might be negative if the given economic unit creates a negative image, repulses other investors and reduces local attractiveness.

In the case of three impacts, the terms of direct, indirect and induced impacts are the most frequent, and in the case of two the direct and the indirect. Classifications when only two or three types of effects are described may be criticised because they blur the line between indirect, induced and catalytic effects while they are easy to distinguish and occur through easily distinguished modes of action, or they simply disregard one of the effects. We concentrate only on direct effects, due to the availability of information.

\section{THE LEVELS OF SETTLEMENT-COMPANY SYMBIOSIS AND THE AUDI COMPANY IN GYÖR}

Settlements and companies are interrelated entities, with lots of common aims and interests. On the first extremes stand the company towns: a town established by a single company, geographically isolated. The company owns the land, builds housing, service facilities, public utilities and entirely dominates the business life of the community, as the sole employer. Acting through self-interest, the company provides and shapes the infrastructure of community. Historically this type of towns was created mainly for mining and other extractive industries (for example, Zlotoryja, Neubulach, Ilmenau, Potosi), and later, in the $19^{\text {th }}$ century for a factory (for example Pullman in Illinois or DuPont in Washington). This type of development was important in the population and settlement history of USA, Canada, South Africa, Russia, Australia (Alanen, 2007; Crawford, 1999; Driscoll, 1984; Porteous, 1970) Contemporary company towns are rare, but big real estate projects are frequent. The wrong sides of these projects are obvious: vulnerability, dependency, risk, control, problems of local social life.

Table 3: The biggest companies (according to the number of employees)

in the biggest Hungarian cities

Source: HCSO, Bisnode Kft.

\begin{tabular}{|l|c|l|c|}
\hline City & \multicolumn{1}{|c|}{$\begin{array}{c}\text { Inhabitants } \\
\text { (2015) }\end{array}$} & \multicolumn{1}{|c|}{$\begin{array}{c}\text { Biggest company } \\
\text { (2015) }\end{array}$} & $\begin{array}{c}\text { Number of employees } \\
\text { (2015) }\end{array}$ \\
\hline Debrecen & 203059 & TEVA Gyógyszergyár Zrt. & 2989 \\
\hline Szeged & 162621 & PICK SZEGED Zrt. & 3265 \\
\hline \multirow{2}{*}{ Miskolc } & 158101 & Robert Bosch Energy and Body & 2090 \\
\hline Pécs & Systems Kft. & 1681 \\
\hline Győr & 145347 & Rebert Bosch Power Tool Kft. & 12015 \\
\hline Nyíregyháza & 129568 & Audi Hungária Motor Kft. & 1875 \\
\hline Kecskemét & 118058 & LEGO Manufacturing Kft. & 3817 \\
\hline Székesfehérvár & 111724 & Mercedes-Benz Manufacturing & 4035 \\
\hline
\end{tabular}

On the second extremes stand the "normal" town, where first a settlement was established in the past, then a new company was established in the existing town. In this case, the interesting question is, how big and how dominant is the biggest company of the town. The eight biggest 
Hungarian cities with the biggest employees can be seen on Table 3. These companies are active in industry (except Mecsek Füszért, which is in the retail) and they have only one location.

Concentration or dominance is the biggest in the case of Györ, in West Hungary, where Audi established originally an assembly plant in 1992. The number of employees at Audi, Györ increased step by step (see Figure 1), and today it is the biggest employer of Hungary among those companies, which has only one location. (Hungarian Post, Hungarian Rail and Hungarian Oil companies are bigger in terms of the employees, but they are multilocational organizations). The ratio of the workers in the biggest company and the number of inhabitant is less than $10 \%$ in Györ, which is much less, than in other well-known examples: Wolfsburg has 120 thousand inhabitants and 60 thousand workers in Volkswagen; Ingolstadt: 127 thousand inhabitants, 44,2 thousand workers in Audi; Everett in Washington: 109 thousand inhabitants, 39 thousand workers in Boeing. There are lots of other examples in the same settlement size category, where the dominance is much bigger, and of course, as the size of settlements became smaller, the dominance can be increased even to more workers in the biggest company as the number of inhabitants of the settlement.

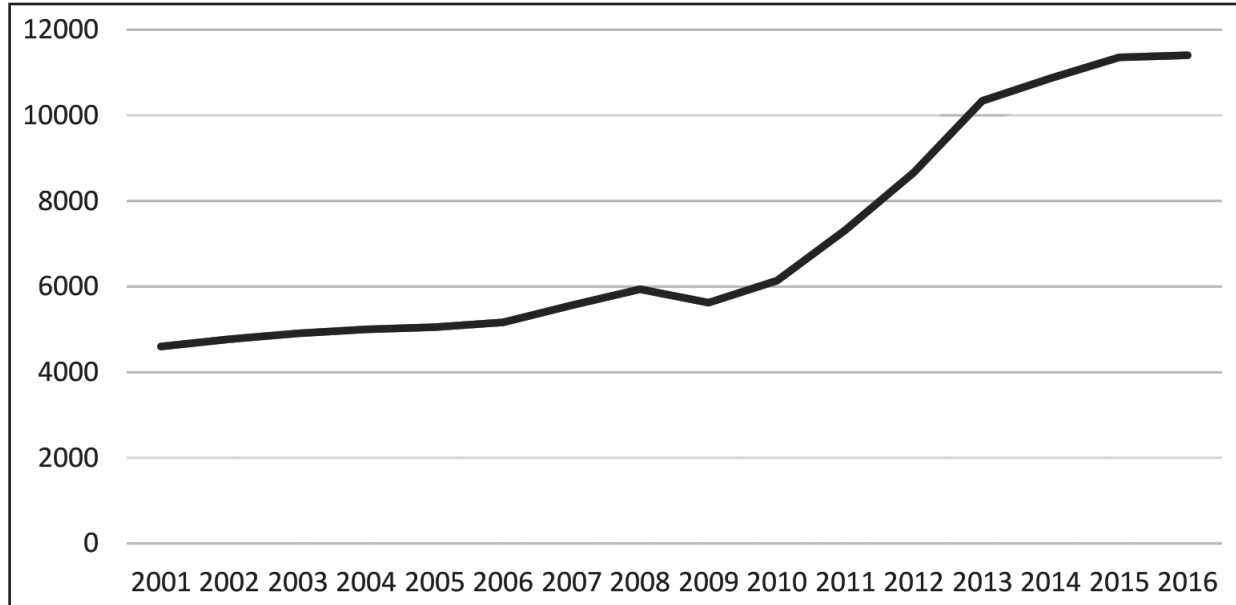

Figure 1: Number of employees in the Audi Hungária (Győr) Source: yearly reports of Audi

The role and importance of Audi in the local society of Györ is a further important research topic. It is regrettable that we can use at this time only public materials about the company which provides very general description and therefore uninteresting, and not suitable for a deeper impact analysis. Therefore, the aim of the next step of our research will be either using interesting internal company level information or broadening the comparison with other settlements.

\section{ACKNOWLEDGEMENTS}

The research was supported by GINOP-2.3.4-15-2016-00003 project.

\section{REFERENCES}

[1] Alanen, A. R. (2007) Morgan Park. Duluth, U.S. Steel, and the forging of a company town. University of Minnesota Press, Minneapolis

[2] Barrow, M., Hall, M. (1995) The Impact of a Large Multinational Organization on a Small Local Economy. Regional Studies, 29, pp. 635-653. 
[3] Beck, R., Elliott, D., Meisel, J., Wagner, M. (1995) Economic impact studies of regional public colleges and universities. Growth and Change, pp. 245-260.

[4] Crawford, M. (1999) The „New” Company Town. Perspecta, 30, pp. 48-57.

[5] Driscoll, J. (1984) Gilchrist, Oregon, a Company Town. Oregon Historical Quarterly, 85, pp. 135-153.

[6] Drucker, J., Goldstein, H. (2007) Assessing the Regional Economic Development Impacts of Universities: A Review of Current Approaches. International Regional Science Review, 30, pp. 20-46.

[7] Garrido-Iserte, R., Gallo-Rivera, M. T. (2010) The impact of the university upon local economy: three methods to estimate demand-side effects. Annals of Regional Science, 44, pp. 49-67.

[8] Grime, E. K., Starkie, D. N. M. (1968) New Jobs for Old: An Impact Study of a New Factory in Furness. Regional Studies, 2, pp. 57-67.

[9] Porteous, J. D. (1970) The nature of company town. Transactions of the Institute of British Geographers, 51, pp. 127-142. 